Mehmet Emin Kalkan ${ }^{1}$, Mustafa Yildiz ${ }^{1,2}$, Hulya Yilmaz Ak ${ }^{2}$, Hicaz Zencirkiran Agus ${ }^{1}$, Yasemin Ozsahin ${ }^{2}$, Ahmet Cagri Aykan ${ }^{3}$, Dogac Oksen ${ }^{2}$

${ }^{1}$ University of Health Sciences Turkey, Mehmet Akif Ersoy Cardiovascular and Thoracic Surgery Educational and Research Hospital, Istanbul, Turkey

${ }^{2}$ Istanbul University-Cerrahpasa Cardiology Institute, Istanbul, Turkey

${ }^{3}$ Kahramanmaras Sutcu Imam University Medical Faculty, Kahramanmaras, Turkey

\title{
SAFETY OF LOW-DOSE PROLONGED INFUSION OF TISSUE PLASMINOGEN ACTIVATOR THERAPY IN PATIENTS WITH THROMBOEMBOLIC EVENTS IN THE INTENSIVE CARE UNIT
}

\begin{abstract}
Objective
Methods

Results

Conclusions

Keywords

For citation

Thromboembolic events such as acute coronary syndrome related prosthetic heart valve thrombosis, pulmonary artery embolism and renal artery embolism are a rare condition but a major cause of morbidity and mortality. In this study we discussed low-dose thrombolytic therapy, in patients with thromboembolic events in the intensive care unit.

The study was performed on 12 consecutive patients [ 8 female; $50.3 \pm 16.0$ (35-95) years] with acute thromboembolism including acute coronary syndrome related prosthetic heart valve thrombosis, acute pulmonary embolism and acute renal embolism who were treated with low-dose $(25 \mathrm{mg})$ and slow infusion (6 hours) of t-PA. We evaluated mainly in-hospital safety and also effectiveness.Total treatment episodes was $1.66 \pm 0.88$ (1-4) times.

All thromboembolic events have been successfully treated with low-dose $(25 \mathrm{mg})$ and slow infusion ( 6 hours) of t-PA. The success criteria were clinically improvement and radiologically lysis. None of the patients had ischemic stroke, intracranial hemorrhage, embolism (peripheral and recurrence of coronary artery embolism), bleeding requiring transfusion. The most frequent in-hospital complication was a gum bleeding without need for transfusion (two patients).

In our case series low-dose $(25 \mathrm{mg})$ and slow infusion (6 hours) of t-PA have been performed successfully for thromboembolic events including acute coronary syndrome related prosthetic heart valve thrombosis, pulmonary embolism and renal embolism in patients with in the intensive care unit. Safety is promising and if efficacy will be proved; this method may be a valuable alternative to standard fibrinolytic regimen.

Thromboembolic events, acute coronary syndrome, pulmonary artery embolism, renal artery embolism, low-dose thrombolytic therapy

Mehmet Emin Kalkan, Mustafa Yildiz, Hulya Yilmaz Ak, Hicaz Zencirkiran Agus, Yasemin Ozsahin, Ahmet Cagri Aykan et al. Safety of low-dose prolonged infusion of tissue plasminogen activator therapy in patients with thromboembolic events in the intensive care unit. Kardiologiia. 2020;60(7):86-90. [Russian: Mehmet Emin Kalkan, Mustafa Yildiz, Hulya Yilmaz Ak, Hicaz Zencirkiran Agus, Yasemin Ozsahin, Ahmet Cagri Aykan и ap. Безопасность Алительной инфузии низкодозной терапии активатором тканевого плазминогена у пациентов с тромбоэмболическими осложнениями, находящихся в отАелении интенсивной терапии. КарАиология. 2020;60(7):86-90]
\end{abstract}

Corresponding author

Hicaz Zencirkiran Agus. E-mail: hicazincir@yahoo.com

\section{Introduction}

Thromboembolic events such as acute coronary syndrome (ACS) associated with prosthetic heart valve thrombosis, pulmonary embolism (PE) and renal embolism are rare conditions, although they appear to be a major cause of morbidity and mortality. Transthoracic echocardiography (TTE), transesophageal echocardiography (TEE), Doppler ultrasonography, computerized tomography (CT) and angiography (coronary, renal, and pulmonary) are important imaging modalities for the diagnosis of these diseases. Systemic fibrinolysis with thrombolytics, usually at high dose and rapid infusion, is recommended as a therapy op- tion in this case [1-3]. However, this regimen may lead to some thromboembolic and haemorrhagic complications in the intensive care unit. To minimise thromboembolic events and haemorrhagic complications due to high and rapid dose of thrombolytics, we previously suggested low-dose $(25 \mathrm{mg}$ ) and slow infusion (6 hours) of tissue plasminogen activator ( $t-\mathrm{PA})$ for prosthetic heart valve disease [4-9]. Here we discuss mainly safety of thrombolytic therapy, low-dose $(25 \mathrm{mg}$ ) and slow infusion (6 hours) of $\mathrm{t}-\mathrm{PA}$, in patients with thromboembolic events including ACS associated with prosthetic heart valve thrombosis, PE and renal artery embolism in the intensive care unit. 
Figure 1. (A) Prosthetic mitral valve thrombus in the transesophageal echocardiography (white arrow).

(B, C) Successful lysis of thrombus on the prosthetic mitral valve (opened and closed position)
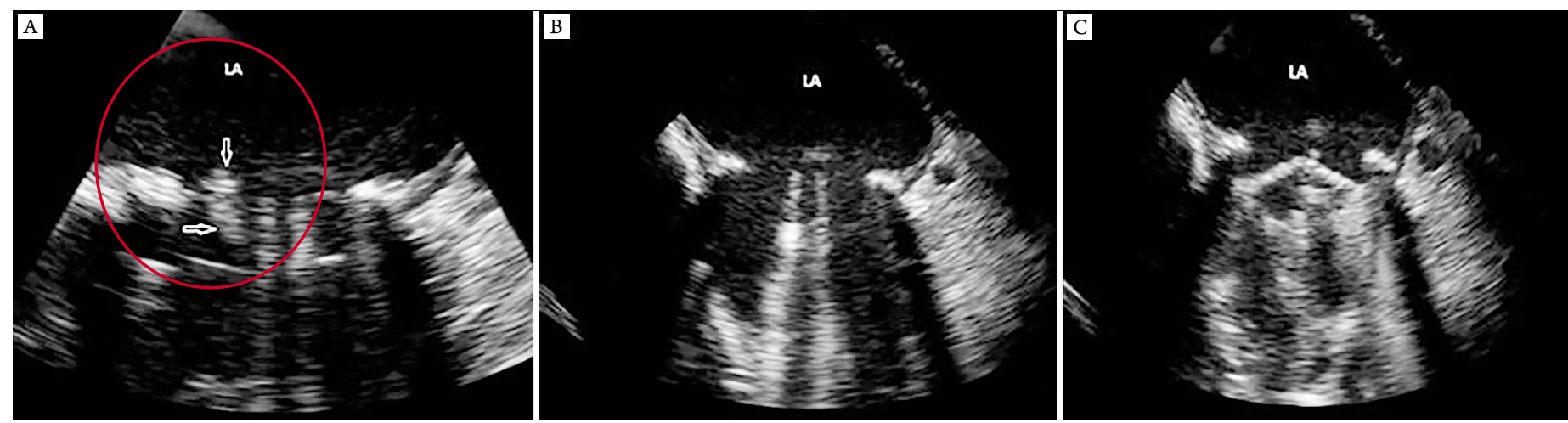

LA: Left atrium.

Methods

\section{Patient population}

We evaluated 12 consecutive intensive care patients with acute thromboembolism [ 8 female; $50.3 \pm 16.0$ (35-95) years] including ACS associated with prosthetic heart valve thrombosis $(\mathrm{n}=5)$, acute $\mathrm{PE}(\mathrm{n}=5)$ and a cute renal embolism $(\mathrm{n}=2$, one of patients had prosthetic heart valve) (Table 1). All subjects gave their consent for inclusion in the study. The study was approved by the local ethics committee. Patients with contraindications to thrombolytic treatment were excluded from this study.

\section{Imaging tecniques for thrombus}

All patients with prosthetic heart valve thrombosis underwent TTE and TEE before and within an hour after the thrombolysis sessions, thrombus was visualized in all patients (Fig. 1).

Pulmonary embolism was documented by the TTE and multi-slice CT (Fig. 2). The right ventricle (RV) was enlarged and paradoxical septal motion was present, indicating RV pressure overload. Doppler examination showed moderate tricuspid regurgitation and pulmonary hypertension $(>35 \mathrm{mmHg})$.

Renal artery Doppler ltrasonography was used to visualize renal artery embolism in two patients and was repeated after thrombolytic therapy.

As TEE findings suggested that catheter intervention would be safe and not causative for thromboembolic compromise, coronary and/or renal angiography was performed in patients with ACS and renal embolism associated with prosthetic heart valve thrombosis. Also renal artery angiography was used in patients with renal embolism without prosthetic heart valve and was repeated after the thrombolytic therapy.

\section{Thrombolytic therapy procedure}

While seven patients were prescribed aspirin, 6 patients were using warfarin. A subtherapeutic international nor-
Figure 2. Left pulmonary artery thrombus in the Computed tomography. (A Panel) Axial view: Red arrow representing thrombus. (B Panel) Axial view: Successful lysis of thrombus in the left pulmonary artery is shown in computed tomography
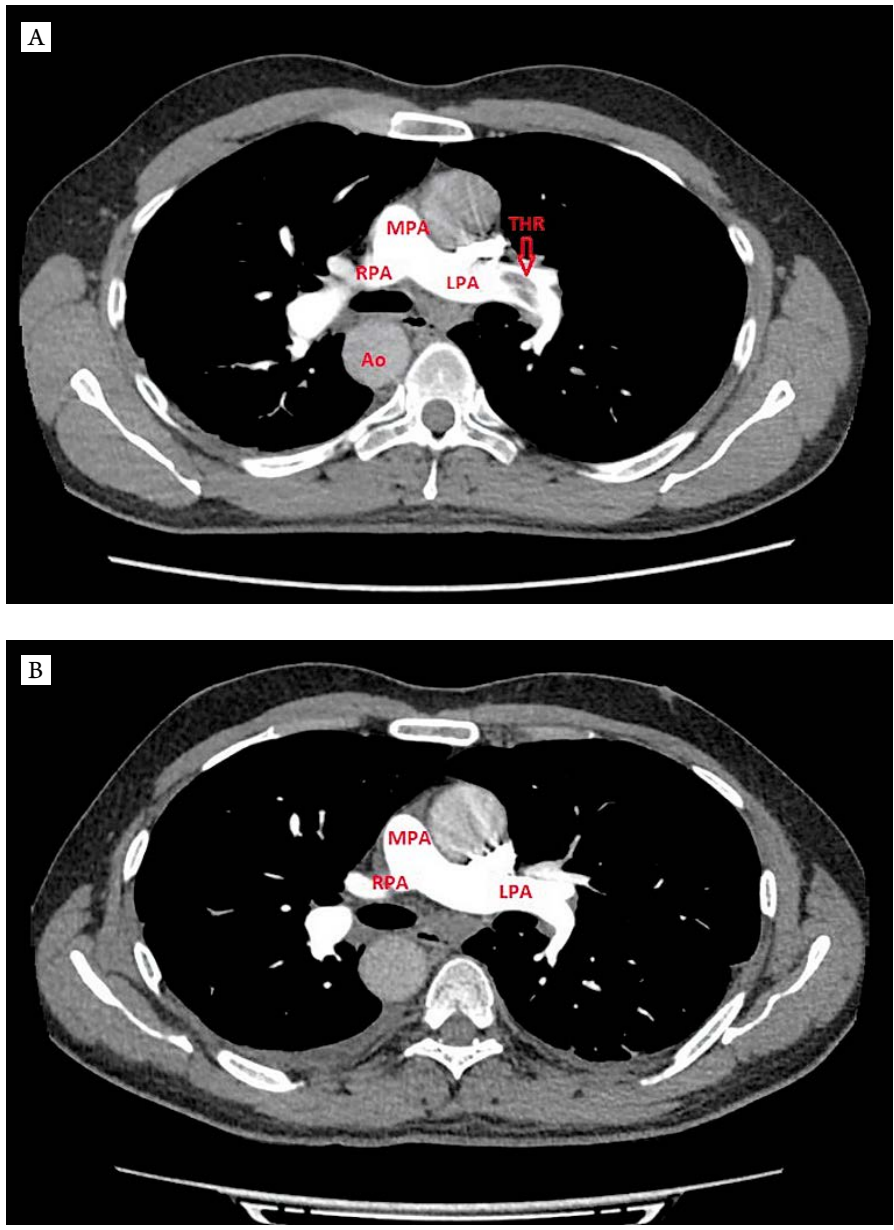

MPA: Mean pulmonary artery, RPA: Right pulmonary artery, LPA: Left pulmonary artery, Ao: Aorta, THR: Thrombus.

malized ratio (INR) $(<1.5)$ was present on admission in six patients with ACS and renal artery embolism associated with prosthetic heart valve thrombosis. 6-h infusion of $25 \mathrm{mg}$ t-PA without a bolus was administered and 
Table 1. Patients characteristics and clinics

\begin{tabular}{|c|c|c|c|c|c|}
\hline $\begin{array}{l}\text { Age, } \\
\text { Sex }\end{array}$ & PHV & Presentation & $\begin{array}{c}\text { Thrombus image } \\
\text { in TTE/TEE*, } \\
\text { anjiography** } \text { CT }^{* * *}\end{array}$ & $\begin{array}{l}\text { Treatment } \\
\text { Episodes }\end{array}$ & Clinic \\
\hline $35, \mathrm{~F}$ & AVR (23 St Jude, bileaflet) & NSTEMI & $\mathrm{PHV}^{*}, \mathrm{LAD}^{* *}$ & 2 & Chest pain \\
\hline $48, \mathrm{~F}$ & AVR (25 Sorin, bileaflet) & NSTEMI & $\mathrm{PHV}^{*}, \mathrm{LAD}^{* *}$ & 2 & Dyspnoea \\
\hline $58, \mathrm{M}$ & AVR (23 St Jude, bileaflet) & NSTEMI & $\mathrm{PHV}^{*}, \mathrm{LAD}^{* *}$ & 2 & Chest pain \\
\hline $45, \mathrm{~F}$ & MVR (29 St Jude, bileaflet) & NSTEMI & $\mathrm{PHV}^{*}, \mathrm{LAD}^{* *}$ & 1 & Chest pain \\
\hline $42, \mathrm{~F}$ & MVR (27 St Jude, bileaflet) & STEMI & $\mathrm{PHV}^{*}, \mathrm{LAD}^{* *}$ & 1 & Chest pain, dispnea \\
\hline $48, \mathrm{~F}$ & MVR (27 St Jude, bileaflet) & Renal Artery Embolism & Left Renal Artery** & 4 & Abdominal pain, anuria, vomitting \\
\hline $59, \mathrm{~F}$ & - & Renal Artery Embolism & Left Renal Artery** & 2 & Abdominal pain, nausea, fever \\
\hline $95 \mathrm{~F}$ & - & PA Embolism & Main and right $\mathrm{PA}^{*}$ & 1 & Dyspnoea, chest pain, tachycardia \\
\hline $51, \mathrm{M}$ & - & PA Embolism & Main PA* & 1 & Hipotension, tachypnoe \\
\hline $37 \mathrm{M}$ & - & PA Embolism & Main PA* $^{*}$ & 1 & Dyspnoea, syncope \\
\hline $37, \mathrm{~F}$ & - & PA Embolism & Iliac veins and lobar $\mathrm{PA}^{* * *}$ & 1 & Dyspnoea, hipotension \\
\hline $49, \mathrm{M}$ & - & PA Embolism & Left PA*** & 2 & Dyspnoea, tachycardia \\
\hline
\end{tabular}

PHV: Prosthetic heart valve, AVR: Aortic prosthetic valve, MVR: Mitral prosthetic valve, TTE: Transthorasic echocardiography, TEE: Transesophageal echocardiography, NSTEMI: Non ST segment elevation myocardial infarction, LAD: Left anterior descending coronary artery, PA: Pulmonary artery, M: Male, F: Female.

repeated once $24 \mathrm{~h}$ later if needed (maximum total dose $150 \mathrm{mg}$ ) [4].

\section{Criteria for thrombolytic success}

For prosthetic heart valves:

1) Doppler ultrasonography documentation of the resolution of increased gradient and decreased valve area.

2) Reduction by $\geq 75 \%$ in major diameter and/or area of the thrombus.

3) Clinical improvement of symptoms such as chest pain, dispnea.

Complete success was defined when all 3 criteria were met. For lung:

1) Echocardiography and/or CT documentation of the resolution of thrombus.

2) Clinical improvement in symptoms such as dyspnoea, hypotension and tachycardia.

Complete success was defined when all 2 criteria were met. For kidney:

1) Renal artery Doppler ultrasonography and/or renal angiography documentation of the resolution of thrombus.

2) Clinical improvement of symptoms such as abdominal pain, anuria and vomitting.

Complete success was defined when all 2 criteria were met.

Patients were followed up in the intensive care unit until thrombolytic success criteria were met. Then, clinical follow ups were performed. If these criteria cannot be met according to the tissue involvement, the repeated dose was initiated. Each patient stayed at the hospital for about a week.

In this study the total number of treatment episodes was $1.66 \pm 0.88$ (1-4) times. Anticoagulation with intravenous unfractionated heparin was withheld during thrombolytic agent infusion. Heparin, $70 \mathrm{U} / \mathrm{kg}$ bolus and $1.000 \mathrm{U} / \mathrm{h}$ infusion with a target activated partial thromboplastin time between 1.5 and 2.5 times the control was started immediately after infusion of the thrombolytic agent. If repeated thrombolytic agent infusion was needed, heparin was withheld until the activated partial thromboplastin time was $<50 \mathrm{~s}$. After thrombolytic success warfarin was restarted while the patient was on intravenous heparin.

\section{Statistical analysis}

Statistics were obtained using the ready-to-use software SPSS version 8.0. All the values such as age were expressed as mean \pm standard deviation and median via descriptive statistics. Categorical variables were defined as percentages.

\section{Results}

Mean age in our study was $50.3 \pm 16.0$ years. 4 (33.3\%) patients were men. Duration of intensive care unit was (1-7) days (median 2.0) and also duration of clinic was (4-5) days (median 4.5) Six patients had mechanical valves (three - aortic and three - mitral valve prosthesis). The most common valve type was the St. Jude Medical (St. Jude Medical Inc., St. Paul, Minnesota) bileaflet valve. Six patients had $\geq 2$ risk factors for atherosclerotic disease such as diabetes mellitus, hypertension and hy_perlipidemia. Seven patients had atrial fibrillation. The findings of angiography, CT and echocardiography are shown in Table 1. No complication occured during angiographic procedures.

Thrombolytic therapy was succeeded in all cases without major complication including ischemic stroke, intracranial 
hemorrhage, embolism (peripheral and recurrence of coronary artery embolism) and bleeding requiring transfusion. All patients improved clinically after treatment. According to type of disease TTE, renal artery Doppler ultrasonography or CT were repeated after trombolytic therapy to show signs of improvement. The most frequent in-hospital complication was a gum bleeding without need for transfusion (two patients). If the thrombolytic criteria was not met, the repeated dose was initiated.

\section{Discussion}

Thromboembolic events such as ACS associated with prosthetic heart valve thrombosis, PE and renal embolism are rare conditions, although they appear to be a major cause of morbidity and mortality.

Prosthetic heart valve disease, especially aortic valve prostheses then mitral prostheses and ACS consequence of thrombosis are rare but dangerous conditions. The majority of these patients with ACS are present with non ST segment elevation myocardial infarction (NSTEMI) $[10,11]$, as in our study. Due to hemodynamic factors which favor diastolic blood flow into the left coronary artery, embolic events generally affect the anterior ventricular wall, as in our study. Optimal management of this condition including systemic thrombolytic therapy, percutaneous transluminal coronary angioplasty and stenting, embolectomy and intracoronary thrombolysis, is controversial [12]. In the present study thrombolytic therapy was considered for the management of prosthetic heart valve thrombosis and concurrent ACS because of soft embolic material. While data proposes the administration of $100 \mathrm{mg}$ t-PA with the usual protocol for acute MI [1], due to its risk of complications, we administered low-dose ( $25 \mathrm{mg}$ ), slow-infusion (6 hours) of t-PA, which was shown to be safe and effective by our group including pregnant and elderly patients with prosthetic heart valve thrombosis [4-9]. At the same time this protocol achieves gradual lysis at the lowest effective dose to minimise thromboembolic events and haemorrhagic complications.

Acute $\mathrm{PE}$ is a potentially lethal condition and it is frequently seen in critical care and emergency medicine. It most often arises from the deep veins of the lower extremity and pelvic vein thrombi. Thrombus causes abnormalities in hemodynamic conditions and gas exchange including ventilation-to-perfusion mismatch, increases in total dead space, and right-to-left shunting. Acute PE leads to an increase of pulmonary vascular resistance and RV afterload due to pulmonary artery vasoconstriction and hypoxemia. The abrupt increase in RV afterload can cause RV dilatation, RV failure, systemic arterial hypotension and cardiac arrest [13]. Most patients are usually tachycardic, tachypnoeic, hypoxic, and hypotensive. Early diagnosis, especially with TTE and multi-slice CT, and treatment are critical to prevent recurrence and decrease morbidity and mortality. TTE in intensive care unit may show a thrombus in the right heart chamber and/or main and/or branches of pulmonary artery. Patients with signs of haemodynamic instability or acute RV failure, classified as intermediate or high-risk $\mathrm{PE}$, have poor outcomes, and trombolytics may be needed to unload the RV. Systemic fibrinolysis with thrombolytics is recommended as standard, first-line treatment in patients with massive acute PE [2]. Although there is no consensus on the thrombolytic therapy protocol, the approved regimen is $100 \mathrm{mg}$ t-PA given during a 2-h infusion [2]. To minimise thromboembolic events and haemorrhagic complications due to high and rapid dose t-PA, we administered low-dose $(25 \mathrm{mg})$ and slow-infusion (6 hours) of t-PA. This treatment regimen may be a reliable choice of treatment in patient with acute PE under the guidance of TTE [14, 15].

Acute thromboembolic occlusion of renal artery is rarely determined in clinical practice. It is generally associated with cardiac diseases and arrhytmias including atrial fibrillation. The most common presentations are the acute onset of flank abdominal pain, nausea, vomiting, anuria and fever. Laboratory findings of acute renal artery embolism may include elevations of white cell count, C-reactive protein, lactic dehydrogenase, and unexplained proteinuria and hematuria. Renal artery Doppler ultrasonography gives important information in the assessment of renal artery occlusion; hence, it is an easily accessible choice of first-line imaging technique at renal artery embolism. The early diagnosis is mostly important to minimize the loss of renal function, since the human kidney tolerates complete ischemia for a few hours [3]. However, there are case reports about recovery of renal function in $24 \mathrm{~h}$ after the revascularization [16]. Successful recovery of renal function after a prolonged period of occlusion can be explained by the presence of collateral vessels from lumbar, suprarenal, and ureteral vessels [17]. Although there is no consensus on the therapy of acute renal embolism; thrombolysis, anticoagulation, or embolectomy may be applied. Finally, restoration of renal function may be seen after revascularization by thrombolytic therapy namely by t-PA [18].

\section{Study limitations}

Our major limitation is small sample size. Study was nonrandomized and no control groups were applied. Sample size and research methodology does not allow to claim effectiveness of the interventions. Data regarding safety are presented.

\section{Conclusion}

In our case series of low-dose $(25 \mathrm{mg})$ and slow infusion (6 hours) of t-PA have been performed successfully. Low- 
dose $(25 \mathrm{mg})$ and slow-infusion (6 hours) of t-PA may be a valuable alternative treatment regimen for thromboembolic events including acute coronary syndrome associated with prosthetic heart valve thrombosis, pulmonary embolism and renal embolism in patients within the intensive care unit. Also successful treatment of both prosthetic heart valve thrombosis and coronary artery thromboembolism with low-dose prolonged infusion of t-PA is observed. Safety is promising, but considering small sample size with different comorbidities; efficacy must be proved with further studies. This method may be a valuable alternative to standard fibrinolytic regimen.

\section{No conflict of interest is reported.}

The article was received on $12 / 03 / 20$

\section{REFERENCES}

1. Rutsch W, Schmutzler H. t-PA in thrombolytic therapy of acute myocardial infarct. Herz. 1994;19(6):336-52. PMID: 7843690

2. Konstantinides SV, Torbicki A, Agnelli G, Danchin N, Fitzmaurice $\mathrm{D}$, Galiè $\mathrm{N}$ et al. 2014 ESC Guidelines on the diagnosis and management of acute pulmonary embolism. European Heart Journal. 2014;35(43):3033-80. DOI: 10.1093/eurheartj/ehu283

3. Koivuviita N, Tertti R, Heiro M, Manner I, Metsärinne K. Thromboembolism as a Cause of Renal Artery Occlusion and Acute Kidney Injury: The Recovery of Kidney Function after Two Weeks. Case Reports in Nephrology and Dialysis. 2014;4(1):82-7. DOI: 10.1159/000362538

4. Özkan M, Gündüz S, Biteker M, Astarcioglu MA, Çevik C, Kaynak E et al. Comparison of Different TEE-Guided Thrombolytic Regimens for Prosthetic Valve Thrombosis. JACC: Cardiovascular Imaging. 2013;6(2):206-16. DOI: 10.1016/j.jcmg.2012.10.016

5. Özkan M, Çakal B, Karakoyun S, Gürsoy OM, Çevik C, Kalçık M et al. Thrombolytic Therapy for the Treatment of Prosthetic Heart Valve Thrombosis in Pregnancy With Low-Dose, Slow Infusion of TissueType Plasminogen Activator. Circulation. 2013;128(5):532-40. DOI: 10.1161/CIRCULATIONAHA.113.001145

6. Gündüz S, Özkan M, Yesin M, Kalçık M, Gürsoy MO, Karakoyun $\mathrm{S}$ et al. Prolonged Infusions of Low-Dose Thrombolytics in Elderly Patients With Prosthetic Heart Valve Thrombosis. Clinical and Applied Thrombosis/Hemostasis. 2017;23(3):241-7. DOI: $10.1177 / 1076029615609698$

7. Yesin M, Kalcik M, Gursoy MO, Yıldız M, Özkan M. Delineation of a giant thrombus on a prosthetic mitral valve successfully thrombolysed with low dose slow infusion of tissue plasminogen activator. Koşuyolu Heart Journal. 2015;18(2):109-10. [Av. at: http://www.kosuyoluheartjournal.com/managete/fu_folder/2015-2/2015-18-2-109-110.pdf]. DOI: 10.5578/khj. $\overline{7} 158$

8. Özkan M, Biteker M, Ekşi Duran N, Yıldız M. Huge Prosthetic Mitral Valve Thrombosis in a Pregnant Woman. Circulation. 2009; 120(18):e151-2. DOI: 10.1161/CIRCULATIONAHA.109.873786

9. Aykan AC, Ozkan M, Duran NE, Yildiz M. Acute ST-elevation inferior myocardial infarction in a patient with a non-obstructive mechanical mitral valve thrombosis : case report - online article. Cardiovascular Journal Of Africa. 2012;23(9):e7-8. DOI: 10.5830/CVJA-2012-047
10. Iakobishvili Z, Eisen A, Porter A, Cohen N, Abramson E, Mager A et al. Acute coronary syndromes in patients with prosthetic heart valves—a case-series. Acute Cardiac Care. 2008;10(3):148-51. DOI: $10.1080 / 17482940701882233$

11. Karakoyun S, Gursoy MO, Kalcik M, Yesin M, Özkan M. A case series of prosthetic heart valve thrombosis-derived coronary embolism. Turk Kardiyoloji Dernegi Arsivi-Archives of the Turkish Society of Cardiology. 2014;42(5):467-71. DOI: 10.5543/tkda.2014.05031

12. Tang L, Hu X, Zhou S. Coronary Artery Embolism Causing Acute Myocardial Infarction in Patients with Mechanical Heart Valve Prosthesis: Which is the Optimal Treatment? Heart, Lung and Circulation. 2014;23(5):422-7. DOI: 10.1016/j.hlc.2013.10.086

13. Goldhaber SZ, Elliott CG. Acute Pulmonary Embolism: Part I: Epidemiology, Pathophysiology, and Diagnosis. Circulation. 2003;108(22):2726-9. DOI: 10.1161/01. CIR.0000097829.89204.0C

14. Yildiz M, Karakoyun S, Acar RD, Ozkan M. Effectiveness of low-dose prolonged infusion of tissue plasminogen activator in a nonagenarian patient with acute pulmonary embolism and main pulmonary artery thrombus: Blood Coagulation \& Fibrinolysis. 2013;24(1):95-6. DOI: $10.1097 /$ MBC.0b013e328359759c

15. Cagri Aykan A, Boyaci F, Hatem E. Successful treatment of a pulmonary embolism with low dose prolonged infusion of tissue typed plasminogen activator in a 37 year old female in early postoperative period. Anadolu Kardiyoloji Dergisi/The Anatolian Journal of Cardiology. 2014;14(4):400-2. DOI: 10.5152/akd.2014.5273

16. Zankl AR, Dengler TJ, Andrassy M, Volz HC, Katus HA, Zeier M. Recovery of renal function after delayed percutaneous dilation of a subtotal in-stent restenosis of the renal artery in a left solitary kidney. Clinical Kidney Journal. 2009;2(3):236-8. DOI: 10.1093/ndtplus/sfp012

17. Abrams HL, Cornell SH. Patterns of collateral flow in renal ischemia. Radiology. 1965;84:1001-12. DOI: 10.1148/84.6.1001

18. Aykan AÇ, Gürsoy OM, Özkan M, Yldz M, Kahveci G, Uslu Z. Successful treatment of renal artery thromboembolism with low-dose prolonged infusion of tissue-typed plasminogen activator in a patient with mitral mechanical heart valve thrombosis under the guidance of multimodality imaging: Blood Coagulation \& Fibrinolysis. 2012;23(7):663-5. DOI: 10.1097/ MBC.0b013e328355e86d 